\title{
REFLEXÃO SOBRE A ATUAÇÃO EM POLÍTICAS PÚBLICAS NO ENSINO DE LÍNGUA INGLESA
}

\author{
Maria Valésia Silva da Silva ${ }^{1}$, Marcia Zambon Farias ${ }^{2}$
}

\begin{abstract}
Resumo: O presente artigo tem como objetivo refletir sobre as Políticas Públicas de que as autoras participaram, participam e que de estarão participando em breve, na área de ensino de Língua Inglesa. Com vistas a responder ao desafio de promover a formação continuada com maiores oportunidades para professores de Inglês como língua estrangeira e internacionalizar a produção acadêmica, algumas políticas de formação de professores têm sido implantadas, a fim de que esses objetivos sejam alcançados. Algumas com foco em professores em formação e outras de formação continuada. Neste artigo, são relatadas as atividades desenvolvidas na REGESD (Rede Gaúcha de Ensino a Distância), no PDPI (Programa de Desenvolvimento Profissional para Professores de Língua Inglesa), no PIBID (Programa Institucional de Bolsas de Iniciação à Docência), sua evolução para a Residência Pedagógica, no Programa ETA (English Teaching Assistant), bem como alguns resultados observados durante o processo. Os referidos projetos têm diferentes objetivos, mas contribuem sensivelmente para o desenvolvimento dos professores de Língua Inglesa, acadêmicos de Letras-Inglês, e consequentemente, podem colaborar para a melhoria do ensino de Língua Inglesa no país.
\end{abstract}

Palavras-chave: Políticas públicas. Formação continuada. REGESD. PDPI. PIBID/UCS. Residência Pedagógica. ETA/UCS.

\section{REFLECTION ON PUBLIC POLICY ACTION IN ENGLISH LANGUAGE TEACHING}

\begin{abstract}
This article aims to report and reflect on the Public Policies the authors were/are using in English Language teaching. These teacher-training policies have been implemented to promote continuing education, academic production, and more opportunities for English teachers. Some of the policies focused on undergraduate students, while others focused on teachers-in-training or life-long learners. This paper will report the activities developed at REGESD (Rede Gaúcha de Ensino a Distância), PDPI (Programa de Desenvolvimento Profissional para Professores de Língua Inglesa), PIBID (Programa Institucional de Bolsas de Iniciação à Docência), and ETA (English Teaching Assistant) programs, as well as their outcomes. The projects have different objectives, but they can greatly contribute to English teachers, English Language academics, and English Language teaching in the country.
\end{abstract}

Keywords: Public policies. Lifelong learning. REGESD. PDPI. PIBID/UCS. Pedagogical Internship. ETA/UCS.

1 Professora Mestra da Universidade de Caxias do Sul.

2 Professora Esp. da Escola Estadual de Ensino Médio Santa Catarina. 


\section{Introdução}

Esse artigo tem o propósito de refletir sobre as experiências da participação das autoras nos seguintes programas de políticas públicas: REGESD (Rede Gaúcha de Ensino a Distância), no PDPI (Programa de Desenvolvimento Profissional para Professores de Língua Inglesa), no PIBID (Programa Institucional de Bolsas de Iniciação à Docência), Residência pedagógica e no Programa ETA (English Teaching Assistant).

Os referidos programas têm diferentes objetivos. A Rede Gaúcha de Ensino Superior a Distância foi formada por oito Universidades gaúchas, CEFET-RS, UNISC, UFPEL, FURG, UFSM, UCS, UERGS, UFRGS, com o intuito de oferecer cursos de graduação em licenciatura, na modalidade a distância, para contribuir com a formação de professores leigos do sistema público de ensino, no âmbito do Programa Pró-Licenciaturas da Secretaria de Educação a Distância do MEC, sendo concluídos em 2011. Nesse programa, a professora Ma. Maria Valésia atuou como autora, professora dos Seminários Integradores e como orientadora de TCC. Já a professora Esp. Marcia atuou como Tutora online do curso.

O PDPI (Programa de Desenvolvimento Profissional para Professores de Língua Inglesa) é um programa de intercâmbio de seis semanas, para professores de inglês de escolas públicas, nos Estados Unidos, em diferentes universidades. A professora Marcia foi para a University of Kansas City Missouri, no estado de Missouri, no período de janeiro e fevereiro de 2013, e a professora Maria Valésia foi para a University of Nebraska-Omaha (UNO), na cidade de Omaha, no estado de Nebraska, nos meses de junho e julho de 2013. O programa havia tido sua última versão em janeiro de 2014, mas voltou a acontecer em janeiro de 2017.

O subprojeto do PIBID Letras/Inglês-UCS é vivenciado por nós, coordenadora de área e supervisora escolar, bem como pelos oito bolsistas envolvidos na Escola Estadual de Ensino Médio Santa Catarina. O PIBID (Programa Institucional de Bolsas de Iniciação à Docência) é uma iniciativa da Coordenação de Aperfeiçoamento Pessoal de Nível Superior (CAPES) que objetiva inserir o acadêmico nas instituições públicas do ensino básico, conforme site institucional:

O Pibid é uma iniciativa para o aperfeiçoamento e a valorização da formação de professores para a educação básica. O programa concede bolsas a alunos de licenciatura participantes de projetos de iniciação à docência desenvolvidos por Instituições de Educação Superior (IES) em parceria com escolas de educação básica da rede pública de ensino. Os projetos devem promover a inserção dos estudantes no contexto das escolas públicas desde o início da sua formação acadêmica para que desenvolvam atividades didático-pedagógicas sob orientação de um docente da licenciatura e de um professor da escola. ${ }^{3}$

3 http://www.capes.gov.br/educacao-basica/capespibid 
Atualmente, as atividades do PIBID estão passando por alterações, o modelo que temos agora, não mais existirá. Ele evoluirá para um novo programa, a Residência Pedagógica. Segundo notícias veiculadas na página do MEC:

\begin{abstract}
A Residência Pedagógica, novo programa para a formação de professores do Ministério da Educação, pretende universalizar o estágio de formação docente como característica de todos os cursos de licenciatura no país. As estratégias para institucionalização dessa nova etapa da formação dos futuros professores brasileiros foram tema do Seminário Residência Pedagógica, que acontece em São Paulo, nesta quinta-feira, 14 (dezembro). A previsão é do oferecimento de $80 \mathrm{mil}$ vagas em 2018.
\end{abstract}

O Programa ETA (English Teaching Assistant), assim como o PIBID e a Residência Pedagógica, têm seu foco na melhoria da qualidade de futuros professores de inglês, alunos de licenciatura em língua inglesa. Conforme site institucional, o referido programa é uma parceria da Coordenação de Aperfeiçoamento de Pessoal de Nível Superior - CAPES, por meio de sua Diretoria de Relações Internacionais - DRI, e a Comissão para o Intercâmbio Educacional entre os Estados Unidos da América e o Brasil (Comissão Fulbright), entidade binacional, criada por troca de Notas Diplomáticas, em 05 de novembro de 1957. Os projetos das Instituições de Ensino Superior (IES) brasileiras devem ser aquelas com curso de bacharelado e/ou licenciatura em Letras, Língua Inglesa. Para tal, estaremos recebendo 4 bolsistas americanos, para desenvolvermos atividades no período de março a novembro de 2018 e 2019. Para esses dois últimos programas, outro texto deverá ser escrito com o relato das atividades desenvolvidas, reflexão sobre os resultados, sobre pontos positivos e negativos, já que em nosso caso o ETA terá sua primeira edição em nossa universidade, e a Residência Pedagógica deverá ter sua versão piloto executada, no estado de São Paulo, em 2018. A seguir, serão descritos com mais detalhes os projetos citados anteriormente.

Os programas acima relacionados compartilham do mesmo objetivo, qual seja, implementar melhorias nos resultados da realidade atual de ensino de Língua Inglesa, com vistas a estabelecer conexões com a perspectiva global de conhecimento.

Nossas reflexões, que serão descritas a seguir, são baseadas na construção de conhecimento e de autonomia proporcionada a professores e alunos durante o processo de interação conforme Vygotsky (1984).

\title{
REGESD- Rede Gaúcha de Ensino a Distância
}

Muitas são as limitações e dificuldades constatadas na formação de professores. A Rede Gaúcha de Ensino Superior a Distância (REGESD), no âmbito do Projeto Pró-Licenciaturas, do MEC, atuou com o objetivo de diminuir o grande número de professores em serviço que não possuía graduação ou formação na área em que estava atuando. Dessa forma, o programa buscou oferecer: 
- Uma primeira graduação para os que ainda não tinham graduação;

- Uma segunda graduação complementar, para professores que possuíam graduação em outra área, mas possuíam bom conhecimento na área de língua estrangeira em que estavam atuando.

A REGESD contou com o envolvimento de oito instituições de ensino superior do estado do Rio Grande do Sul, com atuação em seis cursos distintos. Os professores, bem como os tutores, participaram de cursos de formação específica, pois, para a maioria deles, trabalhar com a plataforma MOODLE era algo novo. A formação aconteceu no ano de 2008, e as aulas iniciaram logo a seguir.

A coordenação do programa ficou a cargo de um comitê gestor formado por Representantes Institucionais de cada IES sob a presidência do Prof. Dr. Sérgio Roberto Kieling Franco (UFRGS) e, localmente, foi coordenado pelo Prof. Dr. Sérgio Faoro Tieppo. No caso da Língua Inglesa, estávamos sob a coordenação da Profa. Dra. Eunice Polônia (UFRGS) e, localmente, pela Profa. Dra. Débora Izé Balsemão Oss (UCS), responsável pelo Pólo de Língua Inglesa, a cargo da Universidade de Caxias do Sul.

A rede foi sustentada por 17 pólos de apoio presencial, e, como já foi dito anteriormente, se desenvolveu na modalidade de ensino a distância. Participaram do Curso de Letras-inglês as seguintes IES: UFRGS, UCS, UFSM, UNISC e foram implementados seis cursos de Graduação em Licenciatura: Artes Visuais, Ciências Biológicas, Geografia, Letras-Espanhol, Letras-Inglês e Matemática.

Conforme orientação do projeto, os professores envolvidos, preferencialmente, deveriam ter participado ou ainda participar da realidade da escola pública, em nosso caso, trabalhávamos juntas na mesma escola pública, o que facilitou sensivelmente nosso trabalho, pela afinidade tecnológica que já desenvolvíamos como colegas de trabalho.

O curso utilizava a plataforma MOODLE, e ficamos responsáveis pelos Seminários Integradores. Após acompanhar os tópicos e conteúdos desenvolvidos pelos colegas das disciplinas do semestre, fazíamos uma reflexão e "amarração metodológica", para que os alunos pudessem compreender e preencher algum ponto que por ventura não tivesse ficado claro.

Aos professores das IES cabia elaborar programas e atividades conforme o projeto institucional e orientações recebidas dos coordenadores. Os tutores $\mathrm{EaD}$ tinham como função sanar as dúvidas referentes aos trabalhos propostos pelos professores, colaborar nos fóruns, participar nos chats online, relembrar os alunos sobre os prazos estabelecidos para a entrega dos materiais e ajudar os professores na correção dos trabalhos propostos. Ficou evidente que muitos dos alunos matriculados no curso não tinham a consciência de que um curso a distância é tão exigente, ou mais, do que um presencial. Que é preciso organização, foco e determinação para cumprir os prazos estipulados, porque as disciplinas ocorriam simultaneamente, como em qualquer curso presencial. Tivemos 
algumas dificuldades com alguns alunos em relação a isso. Alguns prazos precisaram ser ampliados, para que os alunos conseguissem fazer todas as atividades propostas, e que tivessem uma construção de conhecimento efetiva.

Desenvolver a função de tutora foi uma experiência que trouxe vários conhecimentos adicionais à formação de profissional da educação. $O$ fato de sermos também professoras da rede pública acabou contribuindo para o entendimento dos problemas no percurso. Ter a chance de conhecer e trabalhar com a plataforma MOODLE foi de muita valia, foi possível conhecer uma ferramenta que, na época, era nova e poderia trazer mais inovações para a sala de aula.

Embora a Secretaria de Educação-RS tivesse a plataforma MOODLE, não foi possível fazer uso experimental com algumas turmas de alunos, porque, na época, isso era restrito ao uso com professores.

Em relação aos resultados positivos do projeto, podemos destacar ganhos em vários sentidos: (1) formação para professores e tutores sobre os fundamentos do ensino a distância, através da plataforma MOODLE; (2) inclusão de professores/alunos de cidades do interior, que de outra forma não conseguiriam fazer um curso de graduação; (3) inclusão digital de alguns professores/alunos, a melhoria das habilidades de outros; e (4) construção de maior autonomia na aprendizagem e construção de conhecimento por parte de todos os envolvidos no processo.

As maiores dificuldades encontradas foram a alta carga de trabalho dos professores/ alunos e a heterogeneidade de conhecimento da língua inglesa nas quatro habilidades exigidas durante o curso. No entanto, se considerarmos o ponto de partida de cada um, acredita-se que todos obtiveram progressos, alguns precisando mais suporte do tutor $\mathrm{EaD}$, outros menos.

\section{PDPI - Programa de Desenvolvimento Profissional para Professores de Língua Inglesa}

O Programa de Desenvolvimento Profissional para Professores de Língua Inglesa nos Estados Unidos (PDPI) é um programa conjunto entre a Diretoria de Relações Internacionais - DRI e a Diretoria de Formação de Professores da Educação Básica - DEB em parceria com a Embaixada dos Estados Unidos da América no Brasil e com a Comissão Fulbright. Objetiva capacitar professores de língua inglesa da educação básica por meio do fortalecimento do domínio das habilidades linguísticas; do compartilhamento de metodologias de ensino, aprendizagem e avaliação; da experiência in loco em história e cultura dos Estados Unidos; do uso de ferramentas tecnológicas e recursos digitais; e da estimulação de parcerias com universidades e professores americanos.

O PDPI teve sua primeira edição em 2010: enviou 20 professores da rede pública - seja federal, estadual ou municipal, em 2011, 75; em 2012 e 2013, 20 professores de 
cada unidade da Federação, e, em 2017, 479 professores para passarem seis semanas em universidades americanas previamente selecionadas, no último com diferentes critérios para a distribuição de vagas, conforme tabela a baixo.

Quadro 1- Distribuição de vagas 2017

\begin{tabular}{|c|c|c|c|c|}
\hline $\begin{array}{c}\text { Total de } \\
\text { Vagas }\end{array}$ & $\begin{array}{c}\text { Todas Modalidades } \\
\text { de Curso }\end{array}$ & $\begin{array}{c}\text { Desenvolvimento } \\
\text { de Metodologias }\end{array}$ & $\begin{array}{c}\text { Aprimoramento em } \\
\text { inglês } \\
\text { Intermediário I }\end{array}$ & $\begin{array}{c}\text { Aprimoramento } \\
\text { em inglês } \\
\text { Intermediário II }\end{array}$ \\
\hline 479 & $\begin{array}{c}\text { Até de 20 vagas } \\
\text { apenas para } \\
\text { professores egressos } \\
\text { da UAB }\end{array}$ & $\begin{array}{c}\text { Até 7 vagas por } \\
\text { UF }\end{array}$ & Até 5 vagas por UF & $\begin{array}{c}\text { Até 5 vagas por } \\
\text { UF }\end{array}$ \\
\hline
\end{tabular}

Fonte: Das autoras, adaptado de EDITAL no 19/2017. PDPI/ Fulbright

Todos os inscritos realizam uma prova (TOEFL) e, a partir das notas, ocorreu a seleção. A nota alcançada é o 'ponto de corte' para cada uma das possibilidades de curso. Na edição de 2013, quando fomos, havia apenas duas possibilidades: curso de desenvolvimento de metodologia e curso intermediário. Atualmente, existem três níveis de seleção: metodologia, intermediário I e intermediário II.

A professora Marcia fez parte do grupo que passou seis semanas na Universidade de Kansas City Missouri (UMKC) no Missouri. Esse foi um dos poucos, senão o único grupo, que ficou em casa de família. Foi uma experiência única, porque foi possível ver, realmente, como cada família é em seu dia a dia. Além disso, fazer comparações entre a cultura brasileira com a americana $\mathrm{e}$, diariamente, perceber que não existe $\mathrm{o}$ certo ou o errado, mas sim o melhor para cada situação, traz benefícios muito grandes para cada indivíduo e também para a prática educacional.

Foram seis semanas de muito aprendizado e muita socialização de experiências, situações diferentes para as quais cada participante teve que encontrar a melhor maneira de resolver. As aulas aconteciam pela manhã e à tarde. O grupo das metodologias tinha aulas até às $15 \mathrm{~h}$, e o outro grupo, até às $16 \mathrm{~h}$. Após as aulas, os alunos estavam livres para fazerem o que julgavam mais adequado, e surgiram, naturalmente, grupos de pessoas com interesses similares. As próprias universidades UMKC e UNO proporcionaram vários momentos culturais que, certamente, acrescentaram muito à vida de cada participante.

Além dos momentos culturais, os grupos da $U M K C$ e da UNO tiveram oportunidade de visitar escolas públicas americanas, de ensino fundamental e médio, e community colleges. São consideradas community colleges as instituições de ensino superior, que oferecem as disciplinas básicas para vários cursos, com custo reduzido quando comparado às universidades ou faculdades. Elas proporcionam a pessoas de baixa renda a oportunidade de ingressar em um curso superior tendo um gasto reduzido, pelo menos, nos dois primeiros anos. As visitas a essas escolas propiciaram 
aos grupos a oportunidade de observar como as escolas e as community colleges se organizam, de ver como a língua inglesa é trabalhada nesses locais, perceber o quanto as realidades brasileiras e americanas de ensino são diferentes e refletir em qual ponto é possível aproximá-las. As escolas visitadas têm algumas características em comum: são localizadas em bairros mais simples, e os alunos têm uma perspectiva de vida um pouco diferente. Nas escolas para refugiados, eles aprendiam a língua inglesa a partir das estruturas mais simples da língua. Em algumas salas de aula visitadas, o grupo interagiu com os alunos e participou de atividades elaboradas pelos professores brasileiros. Percebeu-se, com muita surpresa, o carinho com que eles trataram o grupo quando souberam que era de brasileiros. A visita aconteceu no início de 2013, um ano antes da Copa do Mundo no Brasil.

É difícil mensurar o quanto essa viagem mudou os participantes enquanto professores em sala de aula. A maioria dos professores deve ser questionado por seus alunos sobre sua experiência no exterior e informar a participação no programa PDPI e isso pode proporcionar aos alunos maior confiança no trabalho, capacidade e conhecimento dos professores. Embora entenda a resistência pelo diferente nível de proficiência dos mesmos, quando se fala dessa oportunidade, comenta-se sobre a prova, o tempo máximo tido para realizá-la, bem como do número mínimo de acertos para um professor ser selecionado, eles percebem o quanto o tempo foi exíguo, o alto número de questões aplicadas na prova, e entendem que não foi uma tarefa tão simples, reconhecem e valorizam mais o esforço de cada professor para fazer parte do grupo selecionado.

Essa oportunidade se amplia para aqueles colegas que viajaram ao exterior, pela primeira vez, através do PDPI. Sabe-se que um professor da rede pública, especialmente da rede pública estadual, não tem muitas condições financeiras de viajar para o exterior, e essa oportunidade pode mudar sua realidade. Cada professor, ao contar suas experiências e histórias vivenciadas em terras americanas, pode servir de exemplo para seus alunos, para que possam perseguir seus sonhos. No período de 2015 e 2016, o programa foi descontinuado, mas retornou no segundo semestre de 2017. Em janeiro e fevereiro de 2018, um novo grupo de professores de inglês da rede pública está tendo a oportunidade de vivenciar o que outros grupos já fizeram em anos anteriores.

\section{PIBID-Programa Institucional de Bolsas de Iniciação à Docência}

O Programa Institucional de Bolsas de Iniciação à Docência (PIBID) é um programa do Governo Federal em conjunto com a CAPES e acontece desde 2008 em várias universidades do país, mas apenas em 2013 a Universidade de Caxias do Sul (UCS) credenciou-se no programa, contemplando várias licenciaturas sendo que ele acontece não apenas no campus de Caxias do Sul, mas também em outros campi da universidade. Desde março de 2014, o PIBID Letras/ Inglês está sendo executado no campus Universitário de Caxias do Sul, na Escola Estadual de Ensino Médio Santa Catarina e tem como finalidade contribuir para a aproximação universidade / escola, 
na formação inicial e continuada na área de ensino da língua inglesa, através do desenvolvimento de uma proposta de letramento e construção social do conhecimento, agregando a tecnologia à rotina da sala de aula. Conforme Schlatter (2009, p. 12):

Em consonância com a proposta dos Parâmetros Curriculares Nacionais -
Ensino Fundamental (Brasil, 1998) e, mais recentemente com as Orientações
Curriculares para o Ensino Médio (2006), entende-se que o ensino de LE
na escola deve focalizar atividades que promovam o letramento, ou seja, a
participação em diferentes práticas sociais que envolvem a leitura e a escrita na
língua materna e na LE. Isso significa que a aula de LE deve criar condições para
que o educando possa engajar-se em atividades que demandam o uso da língua a
partir de temáticas relevantes ao seu contexto e gêneros discursivos variados. As
atividades propostas devem levar em conta o papel da LE na vida do aluno, de
que forma ele já se relaciona (ou não) com essa língua e o que essa LE pode dizer
em relação a sua língua e cultura maternas. Em última análise, aprender a ler e a
escrever (e também ouvir e falar) em determinadas situações de comunicação da
LE tem como meta ampliar a participação do educando nas práticas sociais em sua
língua e em sua cultura, contribuindo para o seu desenvolvimento como cidadão.

O projeto conta, atualmente, com oito bolsistas do curso de Letras/ Inglês, a supervisora escolar e a coordenadora institucional. Através do projeto é possível colocarse em prática, em sala de aula, projetos mais elaborados, que requerem mais preparação e tempo de planejamento, bem como possibilitar aos alunos contato com diferentes ferramentas tecnológicas, ampliando, assim, suas habilidades e competências.

O trabalho é desenvolvido nas oito turmas da professora supervisora, geralmente 5 ou 6 de terceiro ano e o restante do primeiro ou segundo anos, conforme o ano letivo. Os bolsistas vão à escola uma manhã por semana, eles trabalham com as turmas que a professora supervisora tem naquele dia e fazem seus planejamentos nas sextas à tarde, o restante é feito via GOOGLE Drive, para facilitar o trabalho e evitar custos de deslocamento.

Desde o início do trabalho na escola, alguns projetos se repetiram, porque observamos que ajudavam os alunos a desenvolverem suas habilidades em aspectos linguísticos e acadêmicos de forma efetiva, apresentando bons resultados. Uma das oficinas que se repetiu desde o início foi sobre o Google Drive. Foi possível perceber que, com o passar dos anos, aumentou o número de alunos que já conheciam a ferramenta e a usavam para outros fins por já trabalharem ou por fazerem cursos profissionalizantes no turno inverso. A partir da oficina observamos que muitos deram continuidade à utilização da ferramenta para os trabalhos em grupo.

Outra oficina que se repetiu no decorrer dos anos, com ajustes conforme as características de cada turma, foi o trabalho sobre apresentações. Os alunos aprendem como elaborar apresentações digitais: formato, o que colocar e como portar-se em uma apresentação. Como os bolsistas receberam essa formação anteriormente, nas reuniões semanais, os resultados das oficinas puderam ser percebidos por nós e por 
outros professores, em relação aos bolsistas e alunos, já que outras disciplinas também propõem apresentações orais de trabalho.

O desenvolvimento desse subprojeto é composto de quatro etapas. Na primeira, são realizadas leituras e discussões sobre a construção social do conhecimento conforme Vygotsky (1984), com vistas ao embasamento teórico do projeto. A segunda etapa compreende: diagnóstico, planejamento e desenvolvimento das sequências didáticas de língua inglesa. $\mathrm{Na}$ terceira etapa, é realizada a avaliação do trabalho desenvolvido até então, e são propostas melhorias a serem adotadas para os anos seguintes. Finalmente, os oito bolsistas do curso de licenciatura em Letras - Inglês, a supervisora escolar e a coordenadora sistematizam as ações desenvolvidas em forma de relatórios e artigos acadêmicos.

Como pontos positivos, destacamos: (1) foram implantadas novas atividades, e os bolsistas deram bom suporte às aulas de Língua Inglesa da supervisora escolar; (2) os alunos participaram de eventos da Convenção da Associação de Professores de Inglês do Rio Grande do Sul (APIRS), como monitores e puderam aprender um pouco mais sobre apresentações de trabalhos (2014); (3) em julho de 2015 duas bolsistas foram monitoras e apresentaram trabalho sobre as atividades do PIBID-2014 no Fórum das Escolas Públicas; (4) maximização de nossa aproximação universidade/escola; (5) com a ajuda dos bolsistas houve sensivel melhoria na habilidade de Speaking e Listening dos alunos.

Segundo a professora supervisora: "diversos alunos comentaram que, embora não tenham facilidade para falar em inglês, estão entendendo muito mais o que falamos, o que é um bom avanço em um ambiente de escola pública."

A experiência tem sido considerada muito positiva, e a professora/supervisora manifesta sua total aprovação do projeto quando diz:

[...] acredito que todos os professores das escolas públicas deveriam ter a oportunidade de participar do PIBID. Passamos a analisar mais nosso fazer em sala de aula, dedicamos mais tempo para leituras extras e, principalmente, somos instrumentos para que os alunos bolsistas consigam ter a vivência de sala de aula de uma escola pública com qualidade. Alguns até podem já ter experiência como professor, mas a maioria deles são professores de cursos livres, que atuam em uma realidade diferente do ensino regular. Acredito que essa experiência adquirida na escola poderá ser somada à da universidade, enriquecendo as duas realidades envolvidas.

Um dos pontos altos do PIBID, para os bolsistas, é a oportunidade de colocar em prática, em uma sala de aula real - com todos seus aspectos positivos e negativos - o que é visto e estudado na universidade. Fica evidente que, na prática, existem diferenças. Alguns bolsistas, mesmo tendo passado pela escola, não se identificaram com a realidade da sala de aula de escolas públicas. Outros, entretanto, surpreenderam-se ao perceber que gostaram muito e vislumbram possibilidades profissionais nesse sentido. 
Já para a supervisora, o trabalho com os bolsistas proporciona a chance de colocar em prática projetos maiores e mais complexos, pois, muitas vezes, isso não acontece por falta de 'mãos' para trabalhar. Entretanto, o maior benefício é a oportunidade de abrir portas para alunos da licenciatura, para viverem a realidade escola como ela realmente é, o que acontece dentro da escola pública e da sala de aula da escola pública antes de chegarem aos seus estágios supervisionados, proporcionando mais confiança nos seus desenvolvimentos. Embora a crença seja da falta de qualidade da escola pública em geral, compartilhamos com os alunos as experiências positivas, que são possíveis de serem encontradas em várias revistas, como, por exemplo, na Revista Bem legal da UFRGS (http://www.ufrgs.br/revistabemlegal), para que possam se inspirar e ajudarnos na constante melhoria da escola pública. A maioria dos bolsistas comenta que é diferente estar em uma sala de aula como aluna e depois, como bolsista, na posição de professor. Um aspecto interessante é que três bolsistas foram alunos da escola no Ensino Médio e todos reportaram como foi uma experiência gratificante terem sido alunos da escola e, anos depois, voltarem como bolsistas do PIBID.

As dificuldades que as escolas públicas encontram para desenvolver projetos como o que elaboramos estão na falta de infraestrutura adequada para o uso de tecnologias e a heterogeneidade de conhecimento dos alunos ao chegarem ao Ensino Médio, já que a maioria vem de várias escolas da cidade, com diferentes níveis de conhecimento. No que se refere a tecnologias, não tivemos problemas, a escola possui laboratório de informática, no entanto, em alguns momentos, tivemos problemas de funcionamento de alguns, devido à falta de verba para a revisão dos aparelhos.

Outro ponto que dificultou um pouco o trabalho foi o fato de termos tido algumas trocas de bolsistas no decorrer do primeiro semestre de 2014, porque alguns deles tiveram sua iniciação à docência antecipada por oferta de trabalho. Isso poderia ser visto como positivo, mais alunos teriam oportunidade de participar do projeto, no entanto, a cada troca de bolsista, era necessário reorganizar os grupos e horários. Também em relação a esse ponto, foram encontradas dificuldade com a alta rotatividade de professores contratados na escola onde o projeto acontece. Sempre que algum professor novo entra, pode acarretar alterações nos horários e reorganização da agenda de trabalho.

Um ponto a considerar é que, no decorrer dos trabalhos desenvolvidos com os alunos, pôde-se perceber alguns aspectos que os bolsistas precisam melhorar, geralmente no trato com o aluno, pois, querendo ou não, é importante que o professor possa ser um modelo positivo para os alunos e que consiga manter o equilíbrio emocional mesmo nas situações mais difíceis.

Durante o programa, até o presente momento, foram desenvolvidas as seguintes atividades e projetos:

- Preparação para palestra com falante nativo (EUA);

- Oficina sobre apresentações de trabalhos e posteriormente apresentação de trabalhos conforme as orientações recebidas; 
- Projetos e atividades na sala digital, utilizando várias ferramentas conforme a necessidade e com vistas à construção de uma maior autonomia na construção de conhecimento;

- Oficina sobre o ENEM; e

- Organização da Gincana Cultural de Halloween, com o objetivo de fazer a revisão de conteúdos gramaticais e culturais de uma forma lúdica.

No ano de 2015, a boa integração dos bolsistas proporcionou com que as atividades fossem desenvolvidas a contento. No entanto, em 2016, devido ao questionamento da continuidade do projeto pelo governo federal, tivemos um primeiro semestre bastante tumultuado devido às incertezas. Após a aprovação da continuidade, o segundo semestre transcorreu normalmente.

A seguir, falaremos resumidamente sobre os dois programas que ainda estão em implantação e que, da mesma forma, merecerão uma reflexão mais apropriada posteriormente.

\section{Residência Pedagógica}

Embora o programa PIBID seja muito bem-sucedido, ele é considerado restrito. Segundo o diretor da Coordenação de Pessoal de Nível Superior (CAPES), Carlos Lenuzza, "Temos em uma sala de aula de graduação, alunos que tem acesso ao programa e outros não. Já o novo programa de Residência Pedagógica pretende ampliar o número de vagas, de forma que todos os alunos possam ter essa experiência. O coordenador afirma que:

[Se] entendemos que a prática é necessária para a formação de nossos futuros professores, queremos que ela seja para todos. Uma formação global. A meta é alcançarmos a institucionalização para caminharmos para a universalização da formação". Uma formação global. A meta é alcançarmos a institucionalização para caminharmos para a universalização da formação.

O coordenador coloca ainda que será um desafio também para a academia, que precisa aproximar-se mais da escola, incorporar a prática à teoria: "É preciso que a universidade coloque o pé na escola". Ainda segundo ele, "a necessidade da prática tem que estar nos currículos de todos os alunos". No processo de institucionalização do programa, ele deverá ser aberto também aos estudantes não-bolsistas. Conforme reportagem do site do MEC, a professora Guiomar Namo de Mello, consultora executiva, afirma:

A ideia é fazer o Pibid evoluir para a Residência Pedagógica, aliás nada mais natural que ele se torne, de um programa fomentado pelo MEC, para uma norma 
regulamentada pelo $\mathrm{CNE}$, que vaze para os marcos regulatórios obrigatórios da educação.

Como em todo projeto nacional, é importante que se tenha uma boa articulação das instituições de ensino superior, secretarias de educação e escolas, Lenuzza coloca que:

Para efeito sistêmico é fundamental trabalhar com articulação. Saber bem com as secretarias dos mais diversos municípios do Brasil quais são as formações necessárias em cada uma dessas regiões." [...] "Todas as visões hoje presentes no sistema do Pibid estarão mantidas. E pretendemos ainda adicionar a figura do supervisor de rede, para que a atuação fique melhor coordenada.

\section{ETA- English Teaching Assistant Program}

Conforme site do MEC, o Programa de Assistente de Ensino de Língua Inglesa (English Teaching Assistant - ETA) é um Projeto Institucional realizado pela Capes em cooperação com a Comissão para o Intercâmbio Educacional entre os Estados Unidos da América e o Brasil - Comissão Fulbright, que busca selecionar projetos de Instituições de Ensino Superior (IES) brasileiras, para o recebimento de assistentes de ensino de língua inglesa (cidadão estadunidense - falante nativo), com o intuito de contribuir para a elevação da qualidade dos cursos de bacharelado e/ou licenciatura em Letras, Língua Inglesa, na perspectiva de valorizar a formação e a relevância social dos profissionais do magistério da educação básica.

A modalidade do programa é de capacitação e tem duração de nove meses, iniciando em fevereiro de 2018.

\section{Considerações finais}

Primeiramente, gostaríamos de dizer que, independentemente do escopo dos programas, consideramos importante que aconteçam. Nem sempre temos condições ideais, mas cada ação que é feita em direção à qualificação dos professores de inglês é mais uma peça no quebra-cabeça e contribui para a busca da utopia de termos todos os professores de inglês com condições de se qualificar.

É possível observar que cada programa que descrevemos anteriormente tem a intenção de ir em direção ao cumprimento do objetivo principal, melhorar a qualidade do ensino, de inglês, no nosso caso. Alguns são estaduais, o que é o caso do Programa de licenciatura da REGESD, dessa forma, sua abrangência é menor do que a dos outros que são em nível federal, o referido projeto não teve continuidade. Não se tem estudos para afirmar, mas é possível levantar a hipótese de que, de certa forma, o ProUni possa estar sendo uma continuidade da licenciatura de inglês para os alunos de baixa renda, 
entretanto os que não se enquadram nessa faixa de salário, continuam excluídos da gratuidade para cursar licenciatura e ter bolsas para tal.

Outro ponto que foi possível verificar é a dificuldade de se dar continuidade aos programas, entretanto, o Programa PDPI está conseguindo manter a continuidade, teve uma interrupção de dois anos, mas retomou suas atividades em 2017. Desde seu início já proporcionou a qualificação nos EUA de 1.654 professores em oito (8) anos de realização.

Consideramos o PIBID um projeto de alto poder construtivo, que é capaz de concretizar uma melhor relação entre a universidade e a escola. É possível constatar nitidamente que todos os envolvidos no processo são beneficiados e constroem conhecimentos diferenciados, mas interligados, a partir das experiências vividas na escola. Ele propicia a construção de uma relação do mais proficiente com o menos proficiente, que não necessariamente tem relação com a hierarquia dos componentes do grupo. Em vários momentos, principalmente nos cursos tecnológicos, os bolsistas podem ser considerados os mais proficientes, portanto, a construção do conhecimento de suas autonomias é desenvolvida de forma profissional, amigável em várias atividades, tais como: elaboração de sequências didáticas, participação nas aulas da supervisora como monitores e observadores, participação em eventos, produção de resumos expandidos e artigos acadêmicos.

O início das atividades do Programa de Residência Pedagógica, já confirmado para acontecer no estado de São Paulo, em parceria com o Governo de Estado e Prefeitura, poderá vir a ser a continuidade do PIBID, com maior abrangência, beneficiando um maior número de alunos graduandos de licenciatura.

No que se refere ao Programa ETA, ainda não temos como avaliar o impacto que ele pode ter em nossa realidade, porque estaremos participando do mesmo a partir de março de 2018, mas acreditamos que o projeto que tivemos aprovado para $2018 \mathrm{com}$ renovação para 2019, virá para coroar nossos esforços na formação de alunos de Letrasinglês mais proficientes e na internacionalização da Universidade de Caxias do Sul.

\section{Referências}

FREIRE, P. 1996. Pedagogia da autonomia: Saberes necessários à prática educativa. 30 . ed., São Paulo, Paz e Terra, 148p. (Coleção Leitura).

ORIENTAÇÕES CURRICULARES PARA O ENSINO MÉDIO (OCEN). 2006.

Linguagens, códigos e suas tecnologias / Secretaria de Educação Básica. Brasília, Ministério da Educação, Secretaria de Educação Básica. Conhecimentos de línguas estrangeiras, v. 1, p. 85-124.

REFERENCIAIS CURRICULARES DO ESTADO DO RIO GRANDE DO SUL: Linguagens, códigos e suas tecnologias / Secretaria de Estado da Educação - Porto Alegre: SE / DP, 2009. v.1, p. 127-172. 
SCHLATTER, Margarete. O ensino de leitura em língua estrangeira na escola: uma proposta de letramento. Calidoscopio, v. 7, n.1, p.11-23, jan/ abr, 2009.

VYGOTSKY, L. A formação social da mente. São Paulo: Martins Fontes, 1999.

\section{Sites pesquisados na ordem em que são relatados no texto}

<http://www.regesd.tche.br/>

$<$ http://professor.ufrgs.br/eunicepolonia/publications/hipertextos-para-prolicenciatura-emingl\%C3\%AAs-dist\%C3\%A2ncia-da-regesd-2006-porto>

<http://www.capes.gov.br/educacao-basica/capespibid/pibid>

<http://www.capes.gov.br/educacao-basica/capespibid/relatorios-e-dados>

<http://www.capes.gov.br/cooperacao-internacional/estados-unidos/certificacao-em-linguainglesa $>$

$<$ http://www.capes.gov.br/cooperacao-internacional/estados-unidos/programa-de-assistentede-ensino-de-lingua-inglesa-para-projetos-institucionais-capes-fulbright > 